\title{
REFERENCES
}

1. S. Bochner, Boundary values of analytic functions in several variables and of almost periodic functions, Ann. of Math. 45 (1944), 708-722.

2. K. de Leeuw, and I. Glicksberg, Quasi-invariance and analyticity of measures on compact groups, Acta Math. 109 (1963), 179-205.

3. H. Helson, Compact groups with ordered duals, Proc. London Math. Soc. XIV A (1965), 144-156.

4. - Invariant subspaces, Academic Press, New York, 1964.

5. H. Helson and D. Lowdenslager, Prediction theory and Fourier series in several variables. I, Acta Math. 99 (1958), 165-201.

6. - Prediction theory and Fourier series in several variables. II, Acta Math. 106 (1961), 175-212.

7. G. Kallianpur and V. Mandrekar, Representation and multiplicity of purely non-deterministic stochastic processes, Theory of Probability and its Applications $\mathbf{X}$ (1966).

8. G. W. Mackey, A theorem of Stone and von Neumann, Duke Math. J. 16 (1949), 313-326.

9. M. G. Nadkarni, On a class of measures on Bohr group, Pacific J. Math. (to appear).

10. J. von Neumann, Die Eindeutigkeit der Schrödingerschen Operatoren, Math. Ann. (1931), 570-578.

11. F. Riesz and B. Sz-Nagy, Functional analysis, Ungar, New York, 1955.

12. W. Rudin, Fourier analysis on groups, Interscience, New York, 1962.

UNIVERSITY OF MINNESOTA

\section{A NONLINEAR BOUNDARY VALUE PROBLEM}

BY R. WILHELMSEN

Communicated by H. A. Antosiewicz, May 22, 1967

1. Introduction. The main result of this paper establishes the existence of solutions of certain nonlinear two point boundary value problems for a class of nonlinear second order differential equations.

A corollary to the main theorem includes a boundary value problem recently considered by Herbert B. Keller [1] and Klaus Schmitt [2].

2. Definitions. In the following definitions let $\mathbf{S}$ stand for a point set in the $Y Z$-plane.

$$
\begin{aligned}
& A=\{S: S \text { is an arc }\}, \\
& H_{1}=\left\{S:\left(Y_{1}, Z_{1}\right),\left(Y_{2}, Z_{2}\right) \in S \Rightarrow\left(Y_{1}-Y_{2}\right)\left(Z_{1}-Z_{2}\right) \geqq 0\right\}, \\
& H_{2}=\left\{S:\left(Y_{1}, Z_{1}\right),\left(Y_{2}, Z_{2}\right) \in S \Rightarrow\left(Y_{1}-Y_{2}\right)\left(Z_{1}-Z_{2}\right) \leqq 0\right\}, \\
& J_{1}=\{S: \forall \exists(Y, Z) \in S \ni Z=N\}, \\
& J_{2}=\{S: \forall \exists(Y, Z) \in S \ni Y-Z=N\}, \\
& R=\left\{(X, Y, Z): X_{1} \leqq X \leqq X_{2},|Y|+|Z|<\infty\right\}, \\
& B_{0}=\{f(X, Y, Z): f \text { is continuous in } R\},
\end{aligned}
$$




$$
\begin{aligned}
& B_{1}=\left\{f(X, Y, Z): Y_{1}>Y_{2} \Rightarrow f\left(X, Y_{1}, Z\right)>f\left(X, Y_{2}, Z\right)\right\} \\
& B_{2}=\left\{f(X, Y, Z): \exists \text { constant } K \ni\left|f\left(X, Y, Z_{1}\right)-f\left(X, Y, Z_{2}\right)\right|\right. \\
& \left.\leqq K\left|Z_{1}-Z_{2}\right|\right\} .
\end{aligned}
$$

3. The main theorem. Let $L_{1}$ and $M_{1}$ be in $A \cap H_{1} \cap J_{1}$ and let $L_{2}$ and $M_{2}$ be in $A \cap H_{2} \cap J_{2}$. Let $M_{1}$ be bounded above by $L_{1}$; let $M_{2}$ be bounded above and to the right by $L_{2}$, in the sense that there are no points $\left(Y_{M}, Z_{M}\right) \in M_{2}$ and $\left(Y_{L}, Z_{L}\right) \in L_{2}$ such that $Y_{M}>Y_{L}$ and $Z_{M}>Z_{L}$. Let $P_{1}$ be a connected set in the region of the $Y Z$-plane bounded by $L_{1}$ and $M_{1}$, and let $P_{2}$ be a connected set in the region of the $Y Z$-plane bounded by $L_{2}$ and $M_{2}$. Let $P_{1} \in J_{1}$, let $P_{2} \in J_{2}$ and let one of the sets $P_{1}$ and $P_{2}$ be closed.

Theorem. If $F_{a}(X, Y, Z), F_{b}(X, Y, Z)$, and $f(X, Y, Z)$ are in $B_{0}$, $F_{a}$ and $F_{b}$ are in $B_{1} \cap B_{2}$, and $F_{a}(X, Y, Z)>f(X, Y, Z)>F_{b}(X, Y, Z)$ for all $(X, Y, Z) \in R$, then there is a $y(X) \in C^{2}\left[X_{1}, X_{2}\right]$ such that $y^{\prime \prime}(X)=f\left(X, y(X), y^{\prime}(X)\right)$ for all $X \in\left[X_{1}, X_{2}\right], \quad\left(y\left(X_{1}\right), y^{\prime}\left(X_{1}\right)\right) \in P_{1}$ and $\left(y\left(X_{2}\right), y^{\prime}\left(X_{2}\right)\right) \in P_{2}$.

The proof, which will be given in detail elsewhere, utilizes properties of solution funnels of continuous differential equations, developed by H. Kneser [3] and M. Fukuhara [4], and existence theorems for a more restricted class of boundary value problems by M. Lees [5] and J. W. Bebernes [6].

The significance of the theorem is as follows: the function $f(X, Y, Z)$ in the differential equation need not be locally smooth in $Z$ (i.e., no Lipschitz condition is imposed), nor need $f(X, Y, Z)$ be nondecreasing in $Y$; the nonlinear boundary sets $P_{1}$ and $P_{2}$ are quite general, and in particular need not be differentiable curves.

\section{REFERENCES}

1. H. B. Keller, Existence theory for two point boundary value problems, Bull. Amer. Math. Soc. 72 (1966), 728-731.

2. Klaus Schmitt, Solutions to boundary value problems and periodic solutions of second-order nonlinear differential equations, Ph.D. Thesis, University of Nebraska, Lincoln, Nebr., 1967.

3. H. Kneser, Ueber die Lösungen eines Systems gewöhnlicher Differentialgleichungen das der Lipschitzschen Bedingung nicht genügt, S.-B. Preuss. Akad. Wiss. Phys.-Math. Kl. II (1923), 171-174.

4. M. Fukuhara, Sur l'ensemble des courbes integrales d'un systeme d'équations différentielles ordinaires, Proc. Imperial Acad. Japan 4 (1928), 448-449.

5. M. Lees, $A$ boundary value problem for nonlinear ordinary differential equations, J. Math. Mech. 10 (1961), 423-430.

6. J. W. Bebernes, $A$ subfunction approach to a boundary value problem for ordinary differential equations, Pacific J. Math. 13 (1963), 1053-1066.

UNIVERSITY OF UTAH 